\title{
Noninvasive Prenatal Testing - When Is It Advantageous to Apply?
}

\author{
Thomas Liehr $^{\mathrm{a}}$ Angela Lauten ${ }^{\mathrm{b}} \quad$ Uwe Schneider $^{\mathrm{b}} \quad$ Ekkehard Schleussner $^{\mathrm{b}}$ \\ Anja Weise ${ }^{a}$ \\ ${ }^{a}$ Institute of Human Genetics and ${ }^{b}$ Clinic for Obstetrics and Gynecology, Jena University \\ Hospital, Friedrich Schiller University, Jena, Germany
}

\begin{abstract}
What Is It about?
Noninvasive prenatal testing (NIPT) is the most recent development in prenatal diagnostics and based on methods like next-generation sequencing or other high-throughput analysis tools of free placental DNA of the fetus in the serum of maternal blood. As this test is advertised and commercialized in a unique way, we found it interesting to discuss what the basic risks for invasive compared to noninvasive prenatal tests are, what can be expected from NIPT compared to other noninvasive tests, and what the individual pregnant woman can really learn from NIPT. Overall, the medical indications for NIPT are surprisingly limited.
\end{abstract}

\section{Keywords}

Noninvasive prenatal testing $\cdot$ Reliability $\cdot$ Sonography $\cdot$ Reasoning $\cdot$ Loss of pregnancies

\begin{abstract}
Nowadays it is common sense in obstetrics that an increased risk for pregnancy loss due to invasive testing does not exist. Nonetheless, noninvasive prenatal testing (NIPT) is a hot topic, even though this approach does not provide a reduction of unintentionally induced abortions. NIPT has a number of shortcuts which are highlighted in this review, including: (1) in NIPT placental rather than fetal DNA is studied, (2) NIPT fails in 2-6\% of cases, and (3) trisomy 21 accounts for only $\sim 50 \%$ of existing chromosomal aberrations. Thus, we agree with the literature that NIPT is a fascinating possibility to gain information on unborn life from minimal amounts of DNA. However, it remains a pure risk estimation test directed towards the detection of specific chromosomal abnormalities from peripheral blood of the pregnant woman. It is important to highlight that families buying this test, and getting a normal result, may be provided with a false sense of security. Thus, careful and comprehensive genetic counselling should be performed before the test is offered, and should include a clear explanation of the advantages and disadvantages, as well as limitations, compared to other methods.
\end{abstract}




\section{Introduction}

While it was pure science fiction to know anything about the unborn life until the end of the 1950s [1], prenatal diagnostics is a routine approach in today's world. Even though the first unborn child was visualized by sonography in 1958 [2], the majority of invasive routine diagnostic tests starting in the late 1960s [3] was initially done without any sonographic control [4]. Interestingly, Barr-body staining was already performed in 1958 in amnion cells and led to the first antenatal sex determination in history [5].

Amniocentesis (AC), which has been applied since the end of the 19th century in single cases (summarized by Milunsky [6]), became the first routine genetic invasive prenatal test at the end of the 1960s. The herewith acquired amnion cells can be used for fetal chromosomal analyses, and AC is still considered the gold standard for invasive prenatal testing. In addition, the acquisition of chorionic villi samples was introduced as a routine approach in the 1980s; here the goal is to acquire genetic information of the developing child a few weeks earlier than is possible with AC [7]. Even though chorionic villi sampling (CVS) performed with the goal to do genetic studies has been reported before [8-11], it never became routine until the work of Ward et al. [7]. While chromosomes studied from CVS represent placentaderived cells, umbilical cord blood sampling enables chromosomal studies in fetal cells [12]. Interestingly, umbilical cord blood acquisition was already used, for example, for antenatal detection of hemoglobinopathies [13], and applying umbilical cord blood for chromosomal analyses also promoted the use of sonography for sampling of fetal tissues [14, 15]. All invasive tests have advantages and disadvantages, which can be found elsewhere [16] and are in parts discussed below. Apart from standard GTG-banding, many other tests can be performed in fetal-derived cells, like molecular cytogenetic [17-20], molecular genetic [1822], biochemical [16], or immunological tests [16], as well as tests for infections (Table 1).

At the beginning of the 1970s, $\alpha$-fetoprotein was promoted as a promising marker for detection of physical malformations of developing children, especially anencephaly and spina bifida [23]. Even though it is an excellent marker for detection of such malformations and potentially underlying chromosomal aberrations in population genetic approaches, this test fails to be specific enough for reliable individual diagnostics [1]. Other and more reliable biochemical markers were identified later. The best suited biochemical parameters to be determined from maternal peripheral blood were those which were applied for the so-called first-trimester screening test, i.e. pregnancy-associated plasma protein A and free $\beta$-human chorionic gonadotropin [16].

The most recent development in prenatal diagnostics is noninvasive prenatal testing (NIPT) based on high-throughput methods for analyzing free placental DNA of the fetus situated in the serum of maternal blood $[16,24]$. As this test is advertised in scientific journals ( $~ 500$ hits can be found when doing a search for NIPT/NIPD in PubMed [25]), as well as in the daily news, and it is commercialized in a unique way, this article discusses what the basic risks for invasive compared to noninvasive prenatal tests are, what can be expected from NIPT compared to other noninvasive tests, and what the individual pregnant woman can learn from NIPT. At the end, we discuss what the benefits of NIPT are in terms of answering the question, "Is my baby healthy?", and in terms of getting answers in a reasonable time.

\section{Why Do Prenatal Testing?}

As nicely stated by Hixson et al. [16], the reason to be interested in chromosomal aberrations in the unborn is the following: "Chromosomal abnormalities in the fetus constitute one of the leading causes of stillbirth and births of infants with malformations. One type of 
Table 1. List of indications for prenatal diagnostics

Advanced maternal age

Hint for enhanced risk in a noninvasive test

Previous affected child

Sonographic abnormalities

Psychological reasons

Distress and anxiety

Society pressure to have a healthy child

Wish for the "perfect" child

Diagnostics for infections (viral, bacterial, and parasitological)

chromosomal abnormality is aneuploidy, which is defined as the fetus having an extra or missing chromosome. Aneuploidies are caused by errors during the (mitotic or) meiotic cellular division process. During normal meiosis, haploid sperm and egg cells containing one copy of each chromosome are formed from the diploid parent cells. Upon fertilization, a diploid zygote cell is formed, containing two copies of each chromosome, one from each parent. However, errors during meiosis can result in the fetus having an extra or missing chromosome. A number of risk factors can increase the probability of chromosomal aberrations in pregnancy, maternal age being the most important. Down syndrome (DS), which is associated with mental retardation, is the most commonly occurring aneuploidy, with an estimate of 250,700 people living with DS, corresponding to a prevalence of 8.27 per 10,000 individuals. DS is due to the presence of an extra chromosome 21 (trisomy 21). Chromosomal analysis of the fetus is the only way to definitively diagnose DS. Trisomy 18, known as Edwards syndrome, is the next most common aneuploidy, occurring in 1 in 6,000 to 8,000 live births. The probability of survival after birth with this aneuploidy is extremely low, with only about $10 \%$ of infants living more than a year. Trisomy 13 or Pätau syndrome also greatly reduces life expectancy and occurs 1 in 10,000 births. Forty-four percent of children with this condition die within a month of birth."

In Table 1 possible indications for prenatal diagnostics are summarized. However, all of this can be easily broken down to the simple question of a family and/or pregnant woman: "Will my baby be OK?".

\section{Why Avoid Invasive Prenatal Testing?}

All of the relevant textbooks explain that invasive prenatal testing is associated with high risks of involuntarily inducing an abortion. Risk figures provided from the 1980s and 1990s were the bases for defining the cutoff when a pregnant woman has to see an MD due to "advanced maternal age." As nicely stated by Wulff et al. [26], "The risk of miscarriage following CVS and AC was investigated in randomized clinical trials in the 1980s and 1990s. One study found that the risk of miscarriage after AC was increased by $1.0 \%$ compared to the risk with no invasive procedure. Studies have compared CVS with AC and found comparable risk of miscarriage following the two procedures. [...] A recent meta-analysis estimated procedurerelated risks of CVS and AC to be as low as $0.2 \%$ and $0.1 \%$, respectively [27]." Wulff et al. [26] also found that "neither CVS nor AC was associated with increased risk of miscarriage or stillbirth." In Table 2 we provide data that shows the same results; other studies have also confirmed these findings [28-30]. This reduction in pregnancy loss after invasive procedures is mainly due to the application of needles better suited for aspiration and the routine control of the procedure by sonography [28]. 

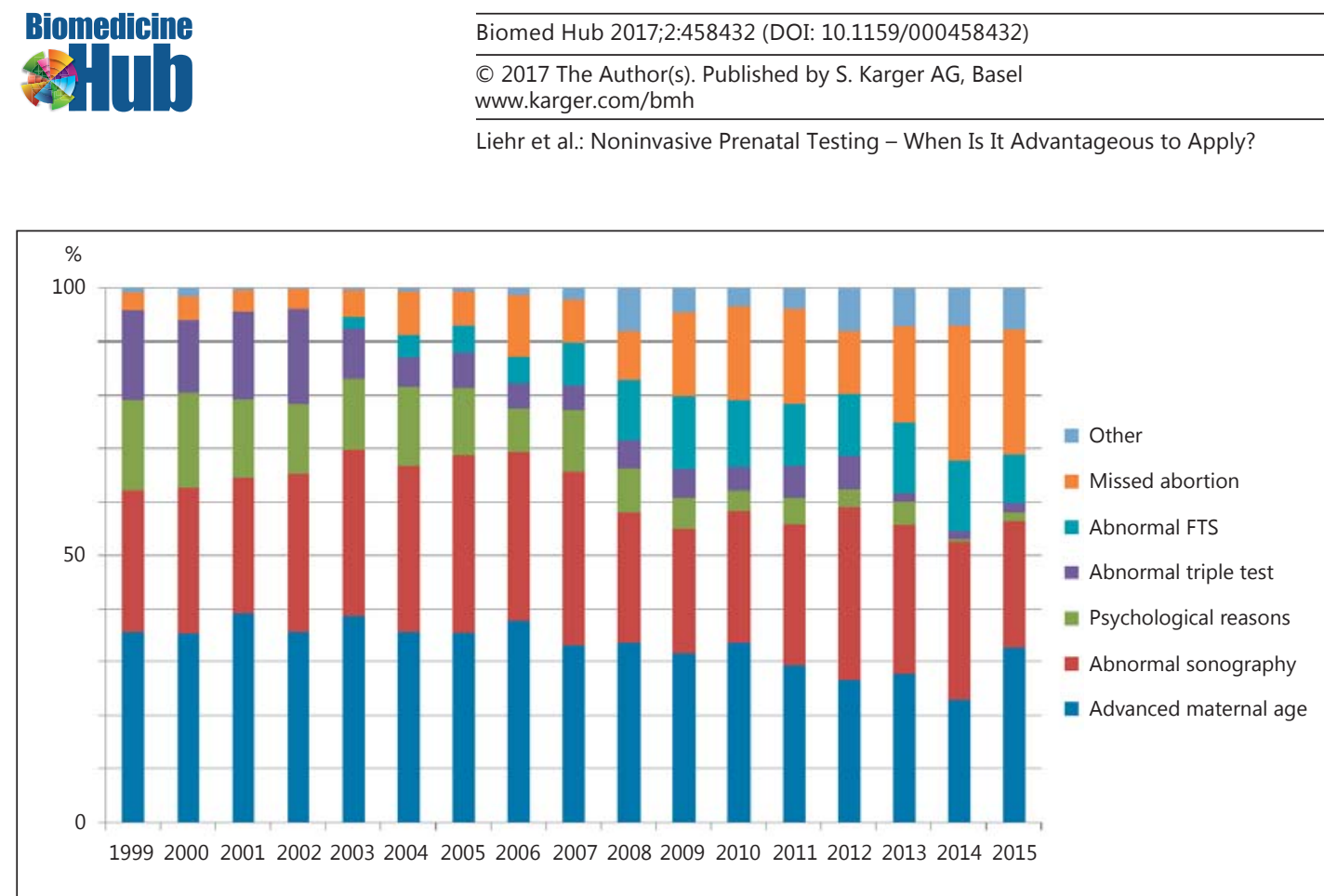

Fig. 1. Development of indications over 17 years in the institute of the corresponding author; 5,280 cases were studied and indications are broken down into 7 main groups. Interestingly, advanced maternal age was and remained the major reason for invasive testing in $\sim 1 / 3$ of the cases. FTS, first-trimester screening.

Table 2. Rate of spontaneous abortions after CVS or AC in Jena between 2010 and 2015

\begin{tabular}{llll}
\hline $\begin{array}{l}\text { Invasive diagnostics } \\
\text { procedure }\end{array}$ & $\begin{array}{l}\text { Abortions/ } \\
\text { number of cases }\end{array}$ & Percentage & $\begin{array}{l}\text { Other events/ } \\
\text { number of cases }\end{array}$ \\
\hline CVS $(10-14$ w.o.g.) & $0 / 44$ & 0 & $0 / 44$ \\
AC $(15-22$ w.o.g.) & $1^{\mathrm{a}} / 311$ & 0.32 & $2^{\mathrm{b}} / 311$ \\
Overall & $1^{\mathrm{a} / 355}$ & 0.28 & $2^{\mathrm{b}} / 355$ \\
\hline
\end{tabular}

AC, amniocentesis; CVS, chorionic villi samples; w.o.g., week of gestation. ${ }^{\text {a }} 1$ case with premature rupture of fetal membranes. ${ }^{\mathrm{b}} 1$ case with intrauterine death of fetus due to toxoplasmosis and 1 case of amnion fluid leakage with spontaneous closure; pregnancy continued.

Thus, an important interim conclusion at this point is that even though an increased risk for pregnancy loss can no longer be substantiated, noninvasive testing is still advertised and/or assumed to be necessary to avoid intervention-associated abortions [31]. Overall, the risk of pregnancy loss due to invasive testing has dropped significantly over the past 2 decades, making the avoidance of invasive testing for this reason less evidence-based. Figure 1 shows the development of indications for invasive prenatal testing. Finally, it can be stated that invasive testing is the best option for pregnancies with sonographically detected abnormalities since, regardless of whether NIPT is normal or abnormal, invasive testing will be recommended to patients who want to determine the etiology of the abnormality in their fetus. 


\section{What Are the Classic Options for Noninvasive Testing?}

The most preferred option of classical NIPT is the application of (high-resolution) sonography. Here the pregnant woman's question as to whether her baby is OK is answered with an accuracy of up to $82 \%$ [32]. Besides, peripheral blood from the pregnant woman can be acquired and biochemical tests can be carried out for PAAP-A and $\beta$-human chorionic gonadotropin. Data from sonography and biochemistry together with age and ethnicity of the pregnant woman can be combined and the results are presented as a risk estimate called the "first-trimester test" [33]. Based on that, any kind of genetic alteration in the developing child can be picked up with a reliability of 91-96\% [16].

\section{What Are the Obstacles of NIPT?}

Having gathered all of the previous data, we should now be prepared to answer questions concerning NIPT:

1. What can be expected from NIPT compared to other noninvasive tests?

2. What can the individual pregnant woman learn from NIPT?

3. What are the benefits of the NIPT in terms answering the question: "Is my baby healthy and how can I find this out with the least possible risk to my baby?"

4. What are the benefits of the NIPT in terms of getting answers in a reasonable time frame?

So let's go through these step by step.

\section{What Can Be Expected from NIPT Compared to Other Noninvasive Tests?}

NIPT can be used not only to detect or exclude a risk for genetic diseases in general, but also specifically. It is possible to directly address the following unbalanced chromosomal alterations: trisomy $13,18,21$, and $\mathrm{X}$ as well as other gonosomal aberrations. What cannot be addressed are, for example, triploidy, balanced chromosomal aberrations, and unbalanced rearrangements involving other genetic regions than the ones of the tested chromosomes. For example, concerning tetrasomy 18p (OMIM No. 614290), the authors know of at least 1 case where the NIPT-analyzing company must have seen a gain of copy numbers in $18 p$, but it went unreported since a whole chromosome was not affected. In the meantime this may have been recognized since such cases have also been reported to have been picked up by NIPT [34]. There are future plans to include frequent microdeletion syndromes in routine NIPT, even though detection rates are, independent from the platform used, not yet convincing [35].

After acquisition of the maternal blood sample, results of NIPT normally take 10-14 days. However, what pregnant women and their families expect from the test is a quick, and clear "yes" or "no" answer to the question of whether the fetus has one of the most frequent chromosomal aberrations of the second trimester. It is possible to apply NIPT at an earlier week of gestation than combined prenatal screening; however, the earlier the gestation week, the lower the amount of free placental DNA in maternal blood. This may lead to specific problems as mentioned below (see point 6). Overall, it is important to remember that the NIPT result is only a risk estimation [36] for the following reasons:

1. Even though literature designates the nonmaternal-derived cell-free DNA in veins of a pregnant woman as "free fetal DNA," everyone knows it is indeed free placental DNA. It 
is more than a truism that placental and fetal genotypes do not coincide in $1-2 \%$ of the pregnancies. Consequently, there have been multiple reports of trisomies detected by NIPT being restricted to the placenta [37-44] or vice versa [43].

2. Thus, also low-level imbalance-mosaicism of the tested chromosomes can never be excluded as one may miss a placental/fetal aberration $[45,46]$.

3. In case of an abnormal NIPT result, invasive testing is recommended by the testing companies, i.e. they consider the possibility of placental mosaicism [47] as well.

4. False-positive results can be detected due to maternal (acquired) mosaicism [48-50], copy number variants present in one parent $[34,38,44,45,51]$, or vanishing twins [51, 52].

5. Cases with unexplained false-positive results have been described several times [38, 41, 53].

6. In $2-6 \%$ of the cases, the free DNA in the mothers' blood does not contain enough "fetal DNA" for a successful test [54]. Still, to find out about that, one needs 10-14 days.

7. If a pregnant woman suffers from obesity, the percentage of cell-free placental DNA is in general lower than in normal weight women and unsuccessful tests become more frequent $(\sim 6 \%)$ [55].

8. As highlighted by Norton et al. [56], trisomy 21 which reaches the highest sensitivity in NIPT accounts only for $~ 50 \%$ of existing chromosomal aberrations compared to invasive diagnostic procedures applying cytogenetics and/or chromosomal microarray, and provide an option for further molecular testing on fetal DNA.

9. The sensitivity to detect trisomy 21 is as high as $99 \%$, but for trisomy 13 and 18 it is "only" 90 and 95\%, respectively [57]; while this is a significant improvement over combined or first-trimester screening, it is not at the level to be considered a diagnostic test.

10. Finally according to guidelines [58] and the literature, NIPT $[59,60]$ is not recommended for women with multiple gestations. The failure rate of NIPT in twins (5.6\%) and placental DNA fraction is in general lower in twins than in singleton pregnancies [59].

\section{What Can the Individual Pregnant Woman Learn from NIPT?}

A pregnant woman doing NIPT can expect 3 kinds of outcomes: no, normal, or abnormal results. A "no test result" can be due to a low fraction of placental DNA. Here the test is repeated to exclude technical problems with another 10- to 14-day delay in decision making. If the test is still not feasible, the pregnancy is actually at higher risk for an adverse outcome [61] and subsequent pregnancy control is recommended.

If the fetus has sonographic abnormalities and NIPT is abnormal, the pregnant woman may know that her baby is affected and she also knows the reason. In case of no sonographic abnormalities and an abnormal NIPT result, an additional invasive test is necessary to confirm the finding is not only a placenta-restricted abnormality.

If sonographic abnormalities are detected and NIPT is normal, additional invasive tests are necessary to find out what is wrong with the fetus. In fact, in this situation, time and expenses for NIPT can be saved by clarifying the situation directly with an invasive diagnostic test.

Even if no sonographic abnormalities are found and NIPT is normal, one can/must do additional invasive tests. This is necessary as a chromosomal abnormality may be only restricted to the fetus or another chromosomal abnormality not detected by the test is possible. However, the pregnant woman can also be happy with the result and do no further tests.

As shown in Figure 2, NIPT may be performed instead of sonography (1), after sonography (2), or after the first-trimester test (3). Advantages and disadvantages of the NIPT are also summarized in Tables 3 and 4. 


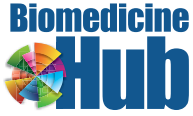

Fig. 2. The 3 major time points for use of NIPT are highlighted in this flowchart in red. NIPT may be done instead of sonography (sono) or first-trimester screening (fTs) (1), after sonography and before/instead of first-trimester screening (2), or after sonography and first-trimester screening (3). In case of abnormal sonography and/or first-trimester screening, invasive prenatal diagnostics is indicated.

(c) 2017 The Author(s). Published by S. Karger AG, Basel www.karger.com/bmh

Liehr et al.: Noninvasive Prenatal Testing - When Is It Advantageous to Apply?

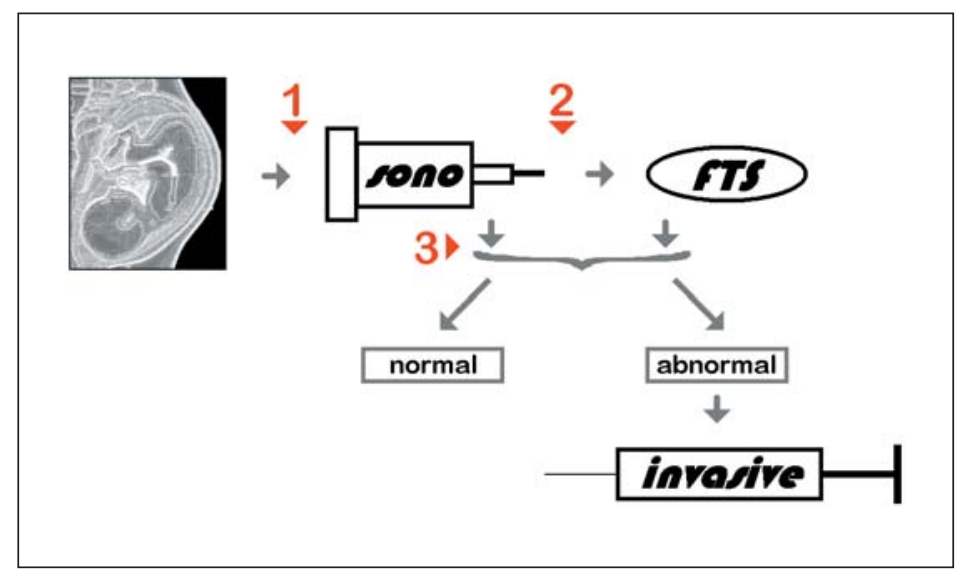

Table 3. General advantages and disadvantages of NIPT with normal or abnormal outcome

\begin{tabular}{lll}
\hline Result of NIPT & Advantages & Disadvantages \\
\hline Normal & $\begin{array}{l}\text { Exclusion of most frequent } \\
\text { aberrations in placenta of fetus }\end{array}$ & $\begin{array}{l}\text { Fetus is not tested genetically } \\
\text { Long time for results } \\
\text { Not all possible genetic changes are detectable } \\
\text { Invasive test may be necessary }\end{array}$ \\
& & Fetus is not tested genetically \\
Abnormal & Detection of an aberration in & Long time for results \\
& placenta of fetus & Invasive test is now necessary anyway \\
\end{tabular}

Table 4. Advantages and disadvantages of doing NIPT at the 3 time points given in Figure 2 are listed

\begin{tabular}{lll}
\hline Time point & Advantages & Disadvantages \\
\hline 1 & DNA is tested, not only phenotype & $\cdot$ Fetus is not tested genetically \\
\hline 2 & DNA is tested, not only biochemistry and & longer time for results \\
& phenotype & Not all possible genetic changes are detectable \\
\cline { 1 - 2 } & Exclusion of most frequent aberrations in & $\cdot$ False-positive and -negative results possible \\
& placenta of fetus & in $3-5 \%$ of cases
\end{tabular}

\section{What Are the Benefits of NIPT in Terms That Answer the Question: "Is My Baby Healthy and How Can I Find This Out with the Least Possible Risk to My Baby?"}

As outlined above, invasive prenatal diagnostics provides very minimally enhanced risks for the unborn. Thus, the major reason for the alleged high need for noninvasive testing has evaporated into nothing over the last years; nonetheless, this argument is still used to advertise NIPT $[16,62]$. 
Fig. 3. When NIPT is performed, the analyses needs an additional time frame of 10-14 days. If NIPT is abnormal, invasive testing is necessary to confirm the result. If NIPT is normal but sonography or first-trimester screening was abnormal, invasive testing is also indicated.

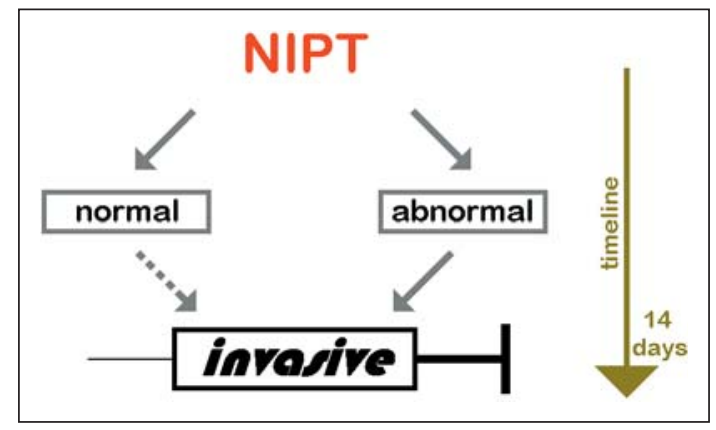

By applying first-trimester screening one can get a 91-96\% reliable risk estimation of whether the fetus may have a trisomy $13 / 18 / 21$ or any 'genetic problem' [4, 16, 33]; with NIPT, studying the placenta and not the fetus, one may detect a maximum of 50\% (trisomy 21 with a high accuracy) of all possible cases with a chromosomal aberration [56].

\section{What Are the Benefits of NIPT in Terms of Getting Answers in a Reasonable Time Frame?}

From the authors' point of view, government-supported NIPT makes sense in countries with a poor "sonographic infrastructure." In all of the industrial countries of Western Europe, Australia, USA, and Canada, NIPT has no recognizable advantage apart from the fact that it is possible to be applied some weeks earlier than combined prenatal screening (with a higher detection rate and lower false-positive rate). Still as NIPT results need $\sim 2$ weeks and thus longer than results of combined (first and second trimester) or first-trimester screening, the results of NIPT may anyways first come when a first-trimester screening could be done.

Invasive diagnostics is indicated in case of abnormal NIPT findings and may be necessary in case of normal NIPT findings (Fig. 3); thus, such pregnancies go on for 2 more weeks due to NIPT before a decision to continue or terminate the pregnancy is reached. As is well known from invasive prenatal chromosome analyses, waiting for genetic results causes severe psychological distress for pregnant women [18], and similar effects can be expected with NIPT.

\section{Conclusions}

NIPT should be considered a screening test of specific chromosomal abnormalities from peripheral blood of a pregnant woman rather than a diagnostic test since its detection rates and false-negative rates for the most commonly targeted aneuploidies are not sufficient to warrant "diagnostic test" status. NIPT offers a fascinating possibility to gain information from minimal amounts of DNA, but the clinical benefit of it is overall quite low [63]. It has to be considered that families buying this test and getting a normal result may be given a false sense of security. Thus, careful and clear genetic counselling has to be done before the test is offered, clearly explaining its advantages and disadvantages as well as limitations compared to other methods. 


\title{
Disclosure Statement
}

\author{
The authors declare no conflicts of interest.
}

\section{Author Contributions}

A.W. and T.L. drafted the paper. A.L., U.S., and E.S. provided the data for Table 2 and edited the paper draft. A.W. provided the data for Figure 1. All authors read and approved the final version of the paper.

\section{References}

1 Darouich AA, Liehr T, Weise A, Schlembach D, Schleussner E, Kiehntopf M, Schreyer I: Alpha-fetoprotein and its value for predicting pregnancy outcomes - a re-evaluation. J Prenat Med 2015;9:18-23.

$\checkmark 2$ Donald I, MacVicar J, Brown TG: Investigation of abdominal masses by pulsed ultrasound. Lancet 1958;1: 1188-1195.

-3 Steele MW, Breg WR Jr: Chromosome analysis of human amniotic-fluid cells. Lancet 1966;1:383-385.

4 Alamillo CM, Fiddler M, Pergament E: Increased nuchal translucency in the presence of normal chromosomes: what's next? Curr Opin Obstet Gynecol 2012;24:102-108.

5 Fuchs F, Riis P: Antenatal sex determination. Nature 1956;177:330.

6 Milunsky A: Genetic Disorders and the Fetus; Diagnosis, Prevention, and Treatment. Berlin, Springer, 1979, pp 19-46.

7 Ward RH, Modell B, Petrou M, Karagözlu F, Douratsos E: Method of sampling chorionic villi in first trimester of pregnancy under guidance of real time ultrasound. Br Med J (Clin Res Ed) 1983;286:1542-1544.

-8 Mohr J: Foetal genetic diagnosis: development of techniques for early sampling of foetal cells. Acta Pathol Microbiol Scand 1968;73:73-77.

9 Kullander S, Sandahl B: Fetal chromosome analysis after transcervical placental biopsies during early pregnancy. Acta Obstet Gynecol Scand 1973;52:355-359.

10 Hahnemann N: Early prenatal diagnosis; a study of biopsy techniques and cell culturing from extraembryonic membranes. Clin Genet 1974;6:294-306.

$>11$ Fetal sex pridiction by sex chromatin of chorionic villi cells during early pregnancy. Chin Med J (Engl) 1975; 1:117-126.

12 Gosden C, Nicolaides KH, Rodeck CH: Fetal blood sampling in investigation of chromosome mosaicism in amniotic fluid cell culture. Lancet 1988;1:613-617.

13 Valenti C: Antenatal detection of hemoglobinopathies. A preliminary report. Am J Obstet Gynecol 1973;115: 851-853.

14 Patrick JE, Perry TB, Kinch RA: Fetoscopy and fetal blood sampling: a percutaneous approach. Am J Obstet Gynecol 1974;119:539-542.

15 Rodeck CH, Campbell S: Umbilical-cord insertion as source of pure fetal blood for prenatal diagnosis. Lancet 1979;1:1244-1245.

16 Hixson L, Goel S, Schuber P, Faltas V, Lee J, Narayakkadan A, Leung H, Osborne J: An overview on prenatal screening for chromosomal aberrations. J Lab Autom 2015;20:562-573.

$\checkmark 17$ Liehr T, Ziegler M: Rapid prenatal diagnostics in the interphase nucleus: procedure and cut-off rates. J Histochem Cytochem 2005;53:289-291.

18 Weise A, Liehr T: Fluorescence in situ hybridization for prenatal screening of chromosomal aneuploidies. Expert Rev Mol Diagn 2008;8:355-357.

19 Weise A, Liehr T: Rapid prenatal aneuploidy screening by fluorescence in situ hybridization (FISH). Methods Mol Biol 2008;444:39-47.

20 Sheth F, Rahman M, Liehr T, Desai M, Patel B, Modi C, Trivedi S, Sheth J: Prenatal screening of cytogenetic anomalies - a Western Indian experience. BMC Pregnancy Childbirth 2015;15:90.

-21 Tantravahi U, Wheeler P: Molecular genetic testing for prenatal diagnosis. Clin Lab Med 2003;23:481-502.

-22 Kang JU, Koo SH: Clinical implementation of chromosomal microarray technology in prenatal diagnosis. (Review). Mol Med Rep 2012;6:1219-1222.

23 Brock DJ, Sutcliffe RG: Alpha-fetoprotein in the antenatal diagnosis of anencephaly and spina bifida. Lancet 1972;2:197-199.

24 Gekas J, Langlois S, Ravitsky V, Audibert F, van den Berg DG, Haidar H, Rousseau F: Non-invasive prenatal testing for fetal chromosome abnormalities: review of clinical and ethical issues. Appl Clin Genet 2016;9: $15-26$. 
25 Pubmed. 2016. https://www.ncbi.nlm.nih.gov/pubmed (accessed October 20, 2016).

-26 Wulff CB, Gerds TA, Rode L, Ekelund CK, Petersen OB, Tabor A; Danish Fetal Medicine Study Group: Risk of fetal loss associated with invasive testing following combined first-trimester screening for Down syndrome: a national cohort of 147,987 singleton pregnancies. Ultrasound Obstet Gynecol 2016;47:38-44.

27 Akolekar R, Beta J, Picciarelli G, Ogilvie C, D’Antonio F: Procedure-related risk of miscarriage following amniocentesis and chorionic villus sampling: a systematic review and meta-analysis. Ultrasound Obstet Gynecol $2015 ; 45: 16-26$

28 Kähler C, Gembruch U, Heling KS, Henrich W, Schramm T; DEGUM: DEGUM guidelines for amniocentesis and chorionic villus sampling (in German). Ultraschall Med 2013;34:435-440.

29 Eddleman KA, Malone FD, Sullivan L, Dukes K, Berkowitz RL, Kharbutli Y, Porter TF, Luthy DA, Comstock CH, Saade GR, Klugman S, Dugoff L, Craigo SD, Timor-Tritsch IE, Carr SR, Wolfe HM, D’Alton ME: Pregnancy loss rates after midtrimester amniocentesis. Obstet Gynecol 2006;108:1067-1072.

-30 Tabor A, Vestergaard CH, Lidegaard Ø: Fetal loss rate after chorionic villus sampling and amniocentesis: an 11-year national registry study. Ultrasound Obstet Gynecol 2009;34:19-24.

-31 Belloin C, Jacquemard F, Bernabé-Dupont C, Viot G, Lohmann L, Grangé G: The noninvasive prenatal testing for Down's Syndrome. Retrospective study of 8821 patients (in French). J Gynecol Obstet Biol Reprod (Paris) 2016;45:1127-1132.

-32 Levi S: Ultrasound in prenatal diagnosis: polemics around routine ultrasound screening for second trimester fetal malformations. Prenat Diagn 2002;22:285-295.

33 Rink BD, Norton ME: Screening for fetal aneuploidy. Semin Perinatol 2016;40:35-43.

-34 Lau TK, Jiang FM, Stevenson RJ, Lo TK, Chan LW, Chan MK, Lo PS, Wang W, Zhang HY, Chen F, Choy KW: Secondary findings from non-invasive prenatal testing for common fetal aneuploidies by whole genome sequencing as a clinical service. Prenat Diagn 2013;33:602-608.

-35 Gross SJ, Stosic M, McDonald-McGinn DM, Bassett AS, Norvez A, Dhamankar R, Kobara K, Kirkizlar E, Zimmermann B, Wayham N, Babiarz JE, Ryan A, Jinnett KN, Demko Z, Benn P: Clinical experience with singlenucleotide polymorphism-based non-invasive prenatal screening for 22q11.2 deletion syndrome. Ultrasound Obstet Gynecol 2016;47:177-183.

-36 Taylor-Phillips S, Freeman K, Geppert J, Agbebiyi A, Uthman OA, Madan J, Clarke A, Quenby S, Clarke A: Accuracy of non-invasive prenatal testing using cell-free DNA for detection of Down, Edwards and Patau syndromes: a systematic review and meta-analysis. BMJ Open 2016;6:e010002.

-37 Lau TK, Cheung SW, Lo PS, Pursley AN, Chan MK, Jiang F, Zhang H, Wang W, Jong LF, Yuen OK, Chan HY, Chan WS, Choy KW: Non-invasive prenatal testing for fetal chromosomal abnormalities by low-coverage wholegenome sequencing of maternal plasma DNA: review of 1982 consecutive cases in a single center. Ultrasound Obstet Gynecol 2014;43:254-264.

-38 Mennuti MT, Cherry AM, Morrissette JJ, Dugoff L: Is it time to sound an alarm about false-positive cell-free DNA testing for fetal aneuploidy? Am J Obstet Gynecol 2013;209:415-419.

-39 Verweij EJ, de Boer MA, Oepkes D: Non-invasive prenatal testing for trisomy 13: more harm than good? Ultrasound Obstet Gynecol 2014;44:112-114.

40 Srebniak MI, Diderich KE, Noomen P, Dijkman A, de Vries FA, van Opstal D: Abnormal non-invasive prenatal test results concordant with karyotype of cytotrophoblast but not reflecting abnormal fetal karyotype. Ultrasound Obstet Gynecol 2014;44:109-111.

41 Chen X, Dai M, Shi W, Pan Y, Zhang W, Zhang Y, Wu Z: Analysis of two false positive cases from noninvasive prenatal testing (in Chinese). Zhonghua Yi Xue Yi Chuan Xue Za Zhi 2014;31:778-781.

42 Pan Q, Sun B, Huang X, Jing X, Liu H, Jiang F, Zhou J, Lin M, Yue H, Hu P, Ning Y: A prenatal case with discrepant findings between non-invasive prenatal testing and fetal genetic testings. Mol Cytogenet 2014; 7:48

43 Grati FR, Malvestiti F, Ferreira JC, Bajaj K, Gaetani E, Agrati C, Grimi B, Dulcetti F, Ruggeri AM, De Toffol S, Maggi F, Wapner R, Gross S, Simoni G: Fetoplacental mosaicism: potential implications for false-positive and falsenegative noninvasive prenatal screening results. Genet Med 2014;16:620-624.

44 Beulen L, Faas BH, Feenstra I, van Vugt JM, Bekker MN: The clinical utility of non-invasive prenatal testing in pregnancies with ultrasound anomalies. Ultrasound Obstet Gynecol DOI: 10.1002/uog.17228.

45 Zhang H, Gao Y, Jiang F, Fu M, Yuan Y, Guo Y, Zhu Z, Lin M, Liu Q, Tian Z, Zhang H, Chen F, Lau TK, Zhao L, Yi X, Yin Y, Wang W: Non-invasive prenatal testing for trisomies 21, 18 and 13: clinical experience from 146,958 pregnancies. Ultrasound Obstet Gynecol 2015;45:530-538.

-46 Van Opstal D, Srebniak MI, Polak J, de Vries F, Govaerts LC, Joosten M, Go AT, Knapen MF, van den Berg C, Diderich KE, Galjaard RJ: False negative NIPT results: risk figures for chromosomes 13, 18 and 21 based on chorionic villi results in 5967 cases and literature review. PLoS One 2016;11:e0146794.

47 Mardy A, Wapner RJ: Confined placental mosaicism and its impact on confirmation of NIPT results. Am J Med Genet C Semin Med Genet 2016;172:118-122.

-48 Osborne CM, Hardisty E, Devers P, Kaiser-Rogers K, Hayden MA, Goodnight W, Vora NL: Discordant noninvasive prenatal testing results in a patient subsequently diagnosed with metastatic disease. Prenat Diagn 2013;33:609-611.

49 Wang Y, Chen Y, Tian F, Zhang J, Song Z, Wu Y, Han X, Hu W, Ma D, Cram D, Cheng W: Maternal mosaicism is a significant contributor to discordant sex chromosomal aneuploidies associated with noninvasive prenatal testing. Clin Chem 2014;60:251-259. 
-50 Snyder MW, Simmons LE, Kitzman JO, Coe BP, Henson JM, Daza RM, Eichler EE, Shendure J, Gammill HS: Copynumber variation and false positive prenatal aneuploidy screening results. N Engl J Med 2015;372:16391645.

-51 Dheedene A, Sante T, De Smet M, Vanbellinghen JF, Grisart B, Vergult S, Janssens S, Menten B: Implementation of non-invasive prenatal testing by semiconductor sequencing in a genetic laboratory. Prenat Diagn 2016;36: 699-707.

52 Lo KK, Karampetsou E, Boustred C, McKay F, Mason S, Hill M, Plagnol V, Chitty LS: Limited clinical utility of non-invasive prenatal testing for subchromosomal abnormalities. Am J Hum Genet 2016;98:34-44.

53 Dugo N, Padula F, Mobili L, Brizzi C, D’Emidio L, Cignini P, Mesoraca A, Bizzoco D, Cima A, Giorlandino C: Six consecutive false positive cases from cell-free fetal DNA testing in a single referring centre. J Prenat Med 2014; 8:31-35.

54 Yaron Y: The implications of non-invasive prenatal testing failures: a review of an under-discussed phenomenon. Prenat Diagn 2016;36:391-396.

-55 Norton ME, Wapner RJ: Cell-free DNA analysis for noninvasive examination of trisomy. N Engl J Med 2015; $373: 2582$

56 Norton ME, Jelliffe-Pawlowski LL, Currier RJ: Chromosome abnormalities detected by current prenatal screening and noninvasive prenatal testing. Obstet Gynecol 2014;124:979-986.

57 Mackie FL, Hemming K, Allen S, Morris RK, Kilby MD: The accuracy of cell-free fetal DNA-based non-invasive prenatal testing in singleton pregnancies: a systematic review and bivariate meta-analysis. BJOG 2017;124: 32-46.

58 Committee Opinion No. 640: cell-free DNA screening for fetal aneuploidy. Obstet Gynecol 2015;126:e31-e37.

59 Bevilacqua E, Gil MM, Nicolaides KH, Ordoñez E, Cirigliano V, Dierickx H, Willems PJ, Jani JC: Performance of screening for aneuploidies by cell-free DNA analysis of maternal blood in twin pregnancies. Ultrasound Obstet Gynecol 2015;45:61-66.

-60 Bevilacqua E, Guizani M, Cos Sanchez T, Jani JC: Concerns with performance of screening for aneuploidy by cell-free DNA analysis of maternal blood in twin pregnancy. Ultrasound Obstet Gynecol 2016;47:124-125.

-61 Krishna I, Badell M, Loucks TL, Lindsay M, Samuel A: Adverse perinatal outcomes are more frequent in pregnancies with a low fetal fraction result on noninvasive prenatal testing. Prenat Diagn 2016;36:210-215.

62 Chiu RW, Akolekar R, Zheng YW, Leung TY, Sun H, Chan KC, Lun FM, Go AT, Lau ET, To WW, Leung WC, Tang RY, Au-Yeung SK, Lam H, Kung YY, Zhang X, van Vugt JM, Minekawa R, Tang MH, Wang J, Oudejans CB, Lau TK, Nicolaides KH, Lo YM: Non-invasive prenatal assessment of trisomy 21 by multiplexed maternal plasma DNA sequencing: large scale validity study. BMJ 2011;342:c7401.

63 Eiben B, Glaubitz R, Kagan KO: Nichtinvasive Pränataldiagnostik, ETS und NGS basierte Tests. Med Gen 2014; 26:382-390. 